NASA/TM-2004-212911

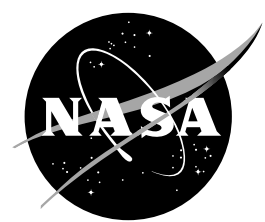

\title{
Assessment of Erosion Resistance of Coated Polymer Matrix Composites for Propulsion Applications
}

Kazuhisa Miyoshi and James K. Sutter Glenn Research Center, Cleveland, Ohio

Richard A. Horan, Subhash K. Naik, and Randall J. Cupp

Allison Advanced Development Company/Rolls-Royce Corporation, Indianapolis, Indiana 
Since its founding, NASA has been dedicated to the advancement of aeronautics and space science. The NASA Scientific and Technical Information (STI) Program Office plays a key part in helping NASA maintain this important role.

The NASA STI Program Office is operated by Langley Research Center, the Lead Center for NASA's scientific and technical information. The NASA STI Program Office provides access to the NASA STI Database, the largest collection of aeronautical and space science STI in the world. The Program Office is also NASA's institutional mechanism for disseminating the results of its research and development activities. These results are published by NASA in the NASA STI Report Series, which includes the following report types:

- $\quad$ TECHNICAL PUBLICATION. Reports of completed research or a major significant phase of research that present the results of NASA programs and include extensive data or theoretical analysis. Includes compilations of significant scientific and technical data and information deemed to be of continuing reference value. NASA's counterpart of peerreviewed formal professional papers but has less stringent limitations on manuscript length and extent of graphic presentations.

- TECHNICAL MEMORANDUM. Scientific and technical findings that are preliminary or of specialized interest, e.g., quick release reports, working papers, and bibliographies that contain minimal annotation. Does not contain extensive analysis.

- CONTRACTOR REPORT. Scientific and technical findings by NASA-sponsored contractors and grantees.
- CONFERENCE PUBLICATION. Collected papers from scientific and technical conferences, symposia, seminars, or other meetings sponsored or cosponsored by NASA.

- SPECIAL PUBLICATION. Scientific, technical, or historical information from NASA programs, projects, and missions, often concerned with subjects having substantial public interest.

- TECHNICAL TRANSLATION. Englishlanguage translations of foreign scientific and technical material pertinent to NASA's mission.

Specialized services that complement the STI Program Office's diverse offerings include creating custom thesauri, building customized databases, organizing and publishing research results ... even providing videos.

For more information about the NASA STI Program Office, see the following:

- Access the NASA STI Program Home Page at http://www.sti.nasa.gov

- E-mail your question via the Internet to help@sti.nasa.gov

- Fax your question to the NASA Access Help Desk at 301-621-0134

- Telephone the NASA Access Help Desk at 301-621-0390

- Write to:

NASA Access Help Desk

NASA Center for AeroSpace Information 7121 Standard Drive

Hanover, MD 21076 
NASA/TM-2004-212911

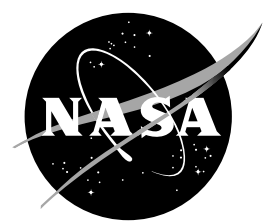

\section{Assessment of Erosion Resistance of Coated Polymer Matrix Composites for Propulsion Applications}

Kazuhisa Miyoshi and James K. Sutter

Glenn Research Center, Cleveland, Ohio

Richard A. Horan, Subhash K. Naik, and Randall J. Cupp

Allison Advanced Development Company/Rolls-Royce Corporation, Indianapolis, Indiana

National Aeronautics and

Space Administration

Glenn Research Center 
This work was sponsored by the Low Emissions Alternative Power Project of the Vehicle Systems Program at the NASA Glenn Research Center.

Trade names or manufacturers' names are used in this report for identification only. This usage does not constitute an official endorsement, either expressed or implied, by the National Aeronautics and Space Administration.

Available from

NASA Center for Aerospace Information 7121 Standard Drive

Hanover, MD 21076
National Technical Information Service 5285 Port Royal Road Springfield, VA 22100

Available electronically at http://gltrs.grc.nasa.gov 


\title{
Assessment of Erosion Resistance of Coated Polymer Matrix Composites for Propulsion Applications
}

\author{
Kazuhisa Miyoshi and James K. Sutter \\ National Aeronautics and Space Administration \\ Glenn Research Center \\ Cleveland, Ohio 44135 \\ Richard A. Horan, Subhash K. Naik, and Randall J. Cupp \\ Allison Advanced Development Company/Rolls-Royce Corporation \\ Indianapolis, Indiana 46206
}

\begin{abstract}
Summary
The erosion behavior of tungsten carbide-cobalt (WC-Co) coated and uncoated polymer matrix composites (PMCs) was examined with solid particle impingement using air jets. Erosion tests were conducted with Arizona road dust impinging at $20^{\circ}, 60^{\circ}$, and $90^{\circ}$ angles at a velocity of $229 \mathrm{~m} \cdot \mathrm{s}^{-1}$ at both 294 and 366 K. Noncontact optical profilometry was used to measure the wear volume loss. Results indicate that the WC-Co coating enhanced erosion resistance and reduced erosion wear volume loss by a factor of nearly 2. This should contribute to longer wear lives, reduced related breakdowns, decreased maintenance costs, and increased product reliability.
\end{abstract}

\section{Introduction}

Polymer matrix composites (PMCs) are facing higher performance requirements and increasingly greater use in aerospace and automotive applications because of their light weight and high strength-toweight ratios relative to metals (refs. 1 to 3 ). These materials, however, have had limited use replacing metals in propulsion applications because PMCs have poor abrasion and oxidation resistance, which contributes to short product lives and restricts their use, especially at high temperatures.

Surface coatings may make possible PMCs that are resistant to erosion wear, sliding wear, and oxidation (ref. 4). Hard coatings have been especially useful in applications involving erosive and abrasive wear. However, simply applying a hard metallic or ceramic coating on softer, tough PMCs to improve erosion and abrasion resistance is not effective since coating durability may be short lived. Increased hardness is usually concomitant with decreased adherence and toughness. Since PMCs generally have higher coefficients of thermal expansion than metallic or ceramic coatings, adhesion strength at the interface between a coating and a substrate may be poor.

One technique commonly used to improve coating adhesion and durability is the use of bondcoats that are interleaved between a coating (topcoat) and a substrate with vastly different coefficients of thermal expansion. Bondcoats sandwiched between high-quality plasma-sprayed, erosion-resistant coatings (topcoats) and PMC substrates have substantially improved the erosion resistance of PMCs (refs. 4 and 5). Chambers et al. (ref. 5) showed that chromium was a suitable interface layer for improved erosion resistance when hard coatings such as $\mathrm{ZrB}_{2}$ were deposited on polyimide substrates. They reported that the use of titanium interface layers under TiC/Ni coatings on polyimide was not successful. Thus, a multicomponent composition of topcoat/bondcoat/PMC must be optimized for the erosion protection of PMCs.

There has been no easy method to accurately measure the erosion wear loss produced on a multilayered (topcoat/bondcoat) system. An even more subtle, yet critical, problem is that these erosion 
coatings contain two or more materials with different densities. Therefore, simply measuring specimen mass loss before and after erosion will not provide an accurate gauge of the volume losses of the multilayered coating system. Erosion wear volume losses have been obtained by measuring crosssectional areas, determined from stylus tracings using stylus profilometry, across the wear scars. Also, coating wear volumes have been determined by cross-sectioning the wear scars and studying the cross sections by optical microscopy (ref. 4). Both techniques are time consuming. Wear measurement by optical microscopy requires sample destruction and does not provide a comprehensive measure of the entire wear volume loss. On the other hand, erosion wear volume losses can be obtained by using noncontact, optical interferometry. This wear measurement technique can provide a comprehensive, accurate determination of the entire erosion wear volume loss for PMCs with multilayered structures while preserving the specimens (ref. 6).

This investigation was conducted to examine the erosion behavior of 36 coated PMC specimens and 18 uncoated PMC specimens subjected to solid particle impingement using air jets. The PMCs were carbon-Kevlar (DuPont, Wilmington, DE) fiber-epoxy resin composites. Prior to topcoating, two types of bondcoats were applied to the 36 PMC substrates: 18 coated specimens had a bondcoat with no polymer and 18 had a bondcoat with a polymer. To both types of bondcoats, tungsten carbide-cobalt (WC-Co) was applied as the primary topcoat constituent. All erosion tests were conducted with Arizona road dust (ARD; AccuBRADE ${ }^{\mathrm{TM}}-10$ (10-mm blend of aluminum oxide), S.S. White Technologies, Piscataway, NJ) impinging at angles of $20^{\circ}, 60^{\circ}$, and $90^{\circ}$ on both coated and uncoated PMCs at a velocity of $229 \mathrm{~m} \cdot \mathrm{s}^{-1}$ at both 294 and $366 \mathrm{~K}$. Noncontact optical profilometry was used to evaluate surface characteristics, such as erosion wear volume loss and depth, surface topography, and surface roughness. Scanning electron microscopy with energy dispersive spectroscopy was used to determine the morphology, erosive and abrasive wear behavior, and elemental composition of the eroded surface.

\section{Materials}

Two types of coatings were applied to carbon-Kevlar (DuPont, Wilmington, DE) fiber-epoxy resin composite engine components-Allison Engines (AE 3007) fan bypass vanes (ref. 7) with a temperature capability up to $393 \mathrm{~K}$. The vane is constructed with a proprietary custom weave with T300, $12 \mathrm{~K}$ tow carbon fiber in a Tactix 123 epoxy matrix: that is, the PMCs were woven from continuous carbon fibers and then epoxy resin transfer molded. Additional inner wrap reinforcements of Kevlar were also used in the vane construction. For both coating systems, WC-Co was the primary topcoat constituent. The coatings included a proprietary bondcoat $(0.076 \mathrm{~mm}$ thick) applied to the PMC substrate followed by a hard topcoat $(0.076 \mathrm{~mm}$ thick). The primary difference between the two types of coatings was that one coating system contained a bondcoat with no polymer and the other contained a bondcoat with a polymer to improve adhesion to the PMC substrate. The bondcoat has a coefficient of thermal expansion (CTE) that bridged the CTE of the PMC and the topcoat.

\section{Experimental Procedure}

\section{Coating Process}

The coating process was adapted from production coating methods. The optimized range for the critical process parameters for the WC-Co topcoat and metal-base bondcoats were identified (ref. 7). The WC-Co topcoat ( $0.076 \mathrm{~mm}$ thick) was applied to both coating systems using a 7MB gun. Engelhard (East Windsor, CT) applied all the coatings. Once spray procedures were established, a design of experiments was instituted to randomly apply the two coating systems on three different days to remove 
potential biases due to spray and ambient conditions. Prior to coating, vanes were randomly chosen from a larger lot at the manufacturer.

Prior to the topcoating, a Sulzer Metco 12E combustion spray gun (Sulzer Metco, Winterthur, Switzerland) with oxygen/acetylene gas was used to apply the bondcoat with no polymer to a thickness of about $0.076 \mathrm{~mm}$. Coating trials were conducted with the part being held stationary or rotated with the gun moving vertically through an automated ladder step control program. Prior to coating, the vanes were carefully grit-blasted with alumina to prepare the surface for deposition.

A Sulzer Metco 7MB plasma spray gun was used to deposit the bondcoat with a polymer to about $0.076 \mathrm{~mm}$. Coating trials to optimize the bondcoat thickness and adhesion were also conducted by varying the gun traverse speed, number of passes, standoff distance, part rotational speed, and argon/nitrogen gas flow ratios.

\section{Erosion Rig Test Procedure}

Erosion testing was performed at the University of Cincinnati (refs. 8 and 9). Specimens (12.5 by $18.5 \mathrm{~mm}$ ) were cut from the coated AE 3007 fan bypass vanes at a set trailing edge location and placed in a test fixture (fig. 1). The fixture was designed to accommodate specimen curvature and to retain the uneroded edge area for a nondestructive evaluation baseline after the erosion test. In addition to providing high temperatures, the University of Cincinnati erosion rig facility (fig. 2) realistically simulates all the erosion parameters that are deemed to be important from an aerodynamic point of view (refs. 8 and 9). These parameters include airflow velocity, impingement angle, erodent particle type and size, and specimen size. Varying the airflow in the erosion rig wind tunnel controlled the particle velocities. Rotating the specimen fixture relative to the flow stream direction set the particle impingement angles. Impingement angles in erosion are defined relative to the plane of the specimen fixture. Heating the flow with a combustible hydrocarbon gas or steam jacket varied the coated PMC specimen temperature. The erosion test procedure used ARD impinging at angles of $20^{\circ}, 60^{\circ}$, and $90^{\circ}$ on both coated and uncoated vane specimens at a velocity of $229 \mathrm{~m} \cdot \mathrm{s}^{-1}$. Room temperature (294 K) and elevated temperature (366 K) tests were conducted using a total of 15,12 , and $10 \mathrm{~g}$ of ARD impinged on each specimen surface at $20^{\circ}$, $60^{\circ}$, and $90^{\circ}$, respectively. A multiple correlation analysis was used to determine the effect of these operational variables on the erosion of the various coating systems.
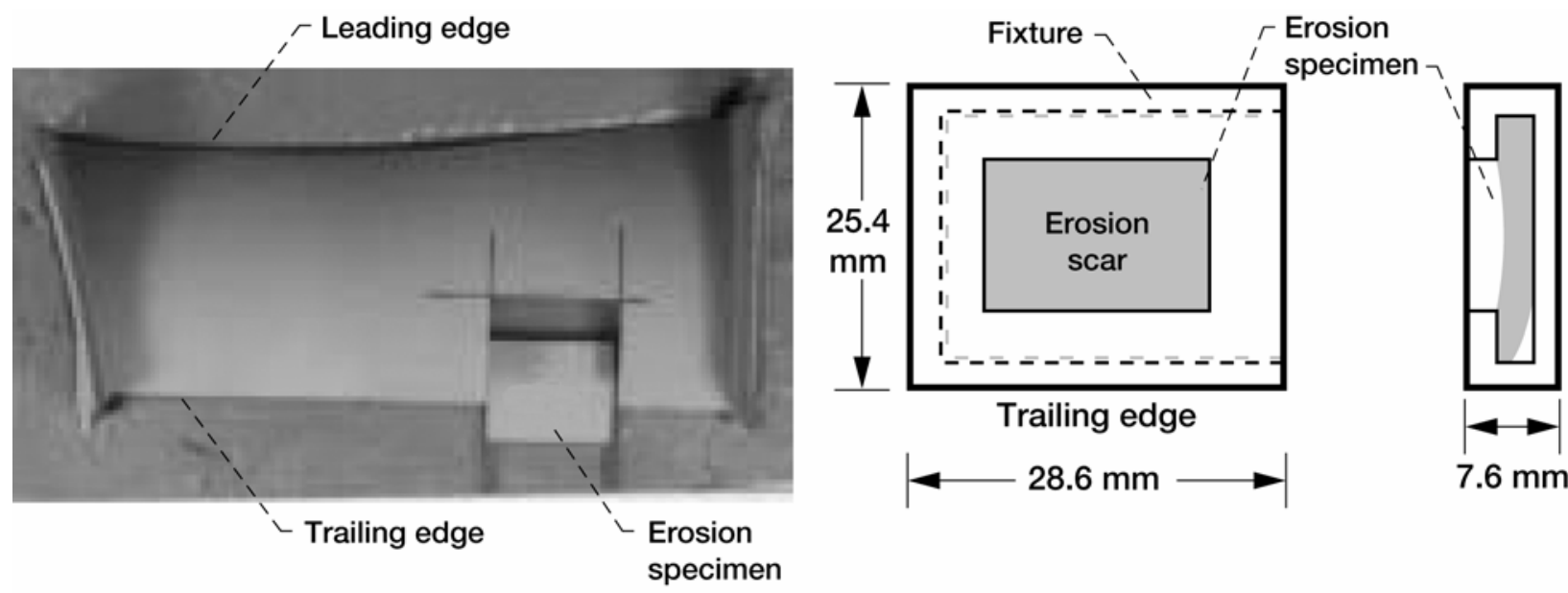

Figure 1. Erosion specimen, fixture, and inserted erosion specimen. 


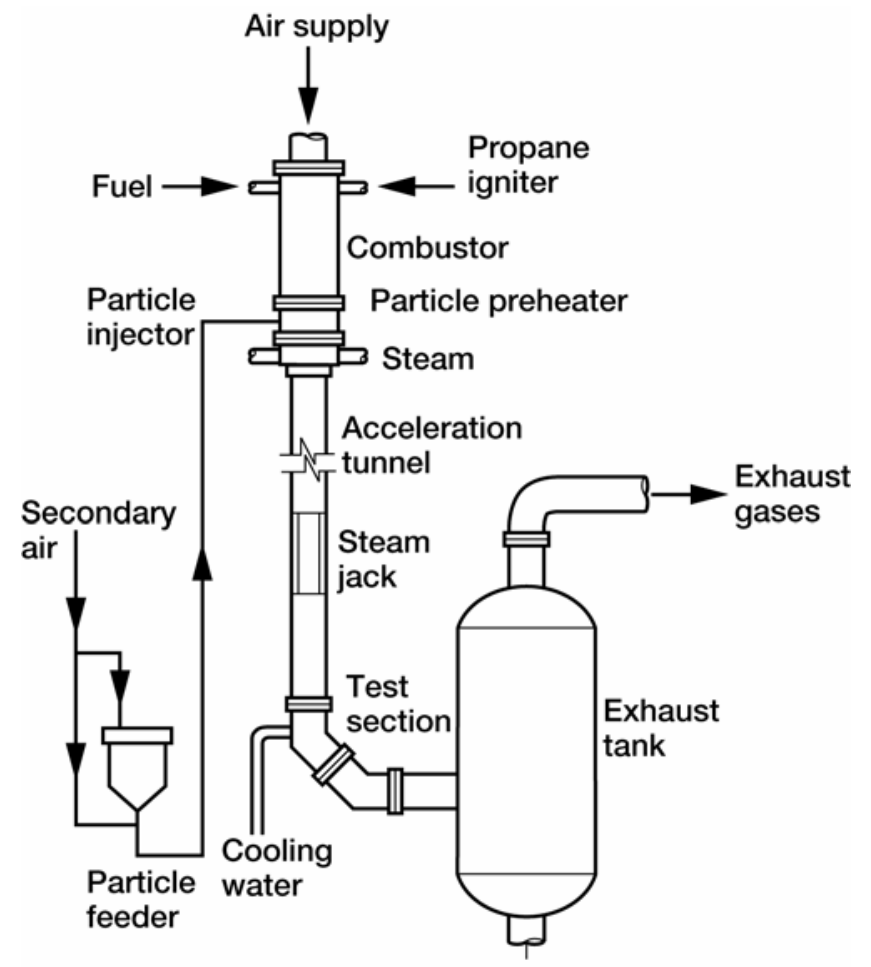

Figure 2. University of Cincinnati's hot erosion rig.

\section{Coating Effectiveness Analysis Procedure}

Erosion wear loss was determined using the following four techniques:

(1) Analytical balance weighing of the mass of the specimen before and after erosion to provide the erosion mass loss (at the University of Cincinnati)

(2) Metallurgical cross-sectioning of the specimen after erosion to measure the erosion depth by photomicroscopy (at Rolls-Royce Corp.)

(3) Optical profilometry measuring of the surface profiles before and after erosion to provide the erosion volume loss and depth loss (at Glenn)

(4) Optical Moiré interferometry measuring of surface profiles before and after erosion to provide the erosion depth loss (at Rolls-Royce Corp.)

The former two are traditional techniques, and the latter two are new nondestructive techniques. Results of a total of 18 specimens (12 coated PMC specimens and 6 uncoated PMC specimens) obtained from each of these techniques were compared with each other to determine if statistically valid correlations existed. It was found that valid correlations existed. Since each uncoated and coated PMC specimen contained more than one constituent and each constituent had a different density, typical erosion mass loss measurement techniques might not provide a reliable means to evaluate erosion loss. A more accurate method would measure the eroded volume loss of the complex coating wear scar. The measurement results obtained indicated that optical profilometry can accurately determine eroded volume losses from complex coating surfaces. 
In this article, therefore, erosion wear volume loss was determined using noncontact optical profilometry (vertically scanning interference microscopy, Veeco Corporation, Tucson, AZ (ref. 10). This technique characterizes and quantifies surface roughness, height distribution, and critical dimensions, such as the area and volume of the damaged erosion wear scars and topographical features. It has three-dimensional profiling capability with excellent precision and accuracy (e.g., profile heights ranging from $\leq 1 \mathrm{~nm}$ to $1000 \mu \mathrm{m}$ with $0.1-\mathrm{nm}$ height resolution). The shape of a surface can be displayed by a computer-generated map developed from digital data derived from a three-dimensional interferogram of the surface, and the volume loss of an eroded surface and the depth of the eroded wear scar can be computed directly. All the measurements were made with an effective magnification of $\times 2.5097$ (a $\times 5$ magnification objective and a $\times 0.5$ eyepiece) that profiled an effective field-of-view with an area of 1.875 by $2.463 \mathrm{~mm}$ and a height sampling of $1000 \mu \mathrm{m}$. The noncontact optical profilometer was regularly calibrated with a step-height measurement standard having a rectangular-shaped groove. The apparent size of the rectangular-shaped groove engraved in the standard was $10 \mu \mathrm{m}$ by $1 \mathrm{~mm}$ by $5 \mathrm{~mm}$.

Two noncontact, optical profilometry methods were used to determine the erosion wear volume loss of the uncoated and coated specimens: the stitching method and the depth-measuring method. For the stitching method, the concave surface of an as-received, uneroded specimen was sampled and measured. Continuous measurements were conducted over a given area. These measurements were stitched together to give a larger sampling area for the specimen (e.g., a 12- by 24-mm area). Before erosion, a given area (e.g., 12.5 by $18 \mathrm{~mm}$ ) of an uneroded vane coupon specimen was analyzed with a noncontact optical profiler (fig. 3(a)). The measurement data were stitched together to give a plot of the stitched area with surface statistics. The natural volume of the stitched area, which the as-received surface before erosion would hold if it were covered just to the nominal surface of the highest peak, was obtained (fig. 3 (b)). In other words, the volume necessary to submerge the stitched area of the vane coupon specimen surface was calculated. This calculated volume is designated $V_{1}$ in this investigation. If an accurate measurement, especially on a rough surface, is to be made, $V_{1}$ should not be neglected. After erosion, the given area $(12.5$ by $18 \mathrm{~mm}$ ) of the eroded specimen was analyzed again with the noncontact optical profiler (fig. 3(c)). The analyzed area was always larger than that of the erosion wear scar. The measurement data were stitched together to give a plot of the stitched area with surface statistics. The natural volume of the stitched area was obtained (fig. 3(d)). This calculated volume is designated $V_{2}$ in this investigation. The erosion volume loss (fig. 3(e)) can be expressed simply as the natural volume of the eroded surface minus the natural volume of the uneroded surface:

$$
\text { erosion volume loss }=V_{2}-V_{1}
$$

Thus, in the stitching method, the erosion wear volume loss was derived from the volume analyses of the three-dimensional contour maps obtained before and after erosion. For the depth-measuring method, the erosion volume wear loss was obtained using the following equation:

erosion volume wear loss $=$ mean erosion depth $\times$ eroded area + net missing volume of eroded surface

- natural volume of uneroded surface

To obtain the average erosion depth of an eroded scar, the erosion depth was measured at eight locations, which are designated in figure 4(a) on an eroded specimen. At each location, noncontact, optical interferometry profiled the surface topography, which included the eroded and uneroded areas. The uneroded area was used as a reference for the erosion depth measurement. Eight contour maps were obtained from each erosion scar. For each contour map, the maximum erosion depth was obtained by measuring a step height between a nominal surface and the zero level of the bottom wear surface of the erosion scar in the cross-sectional profile (a two-dimensional slice of a surface) of the map. Then, the mean value of the eight maximum erosion depths was determined and defined as the mean erosion depth (fig. 4(b)). 


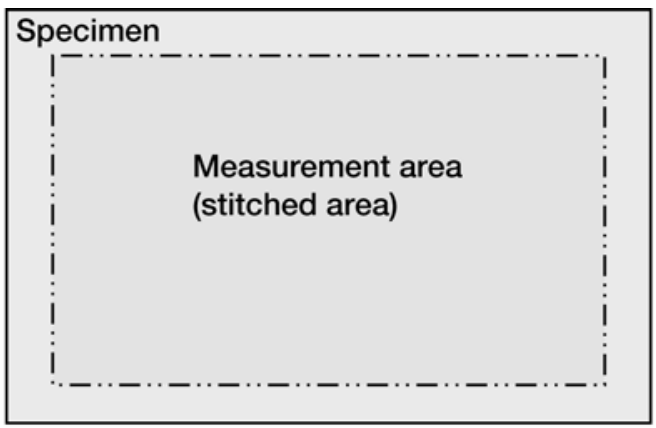

(a)

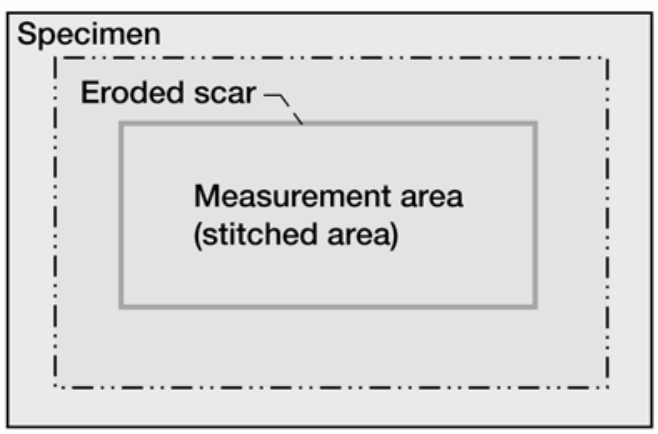

(c)
Trailing edge

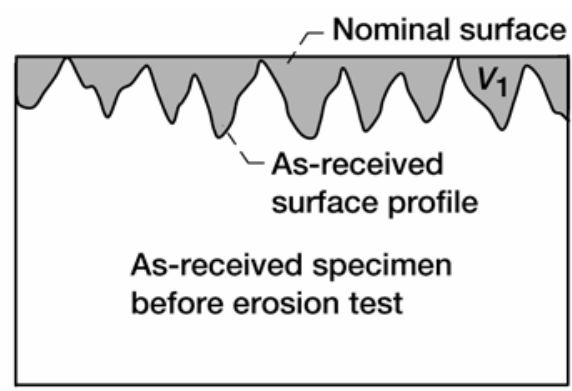

(b)

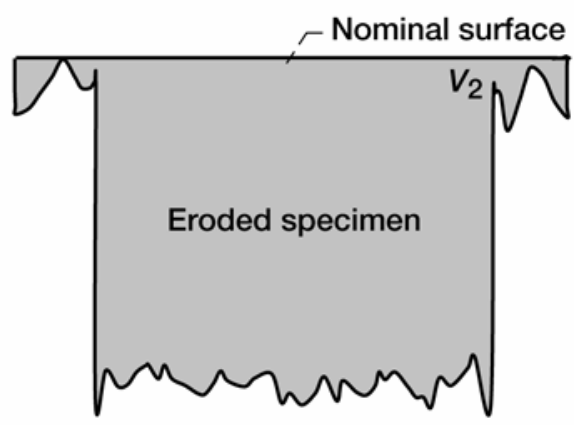

(d)

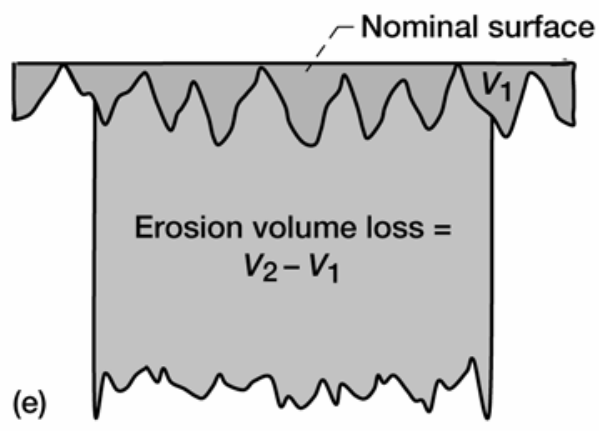

Figure 3. Stitching method. (a) Measurement of uneroded specimen. (b) Natural volume, $V_{1}$, of uneroded surface. (c) Measurement of eroded specimen. (d) Natural volume, $V_{2}$, of eroded specimen. (e) Erosion volume loss.

The eroded area was determined from measurements of the four sides of the rectangular-shaped erosion scar made using both an optical microscope with two micrometers and electronic digital calipers. The area of the eroded rectangle was expressed as the mean of the long side times the mean of the short side.

After erosion, the net missing volume of the eroded area was measured at eight random locations in the eroded wear scar. Then, the total net missing volume of the whole eroded area was calculated. The net missing volume is equal to the negative volume minus the positive volume in the eroded area (fig. 4(c)), where the negative volume is the volume above the bottom wear surface of an erosion scar and below the zero level, and the positive volume is the volume below the bottom wear surface of the erosion scar and above the zero level. In general, the negative volume was almost equal to the positive volume so that the net missing volume of the eroded area was negligible. 


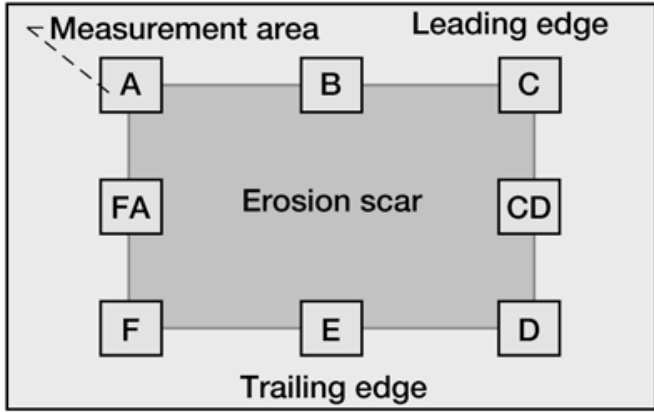

(a)
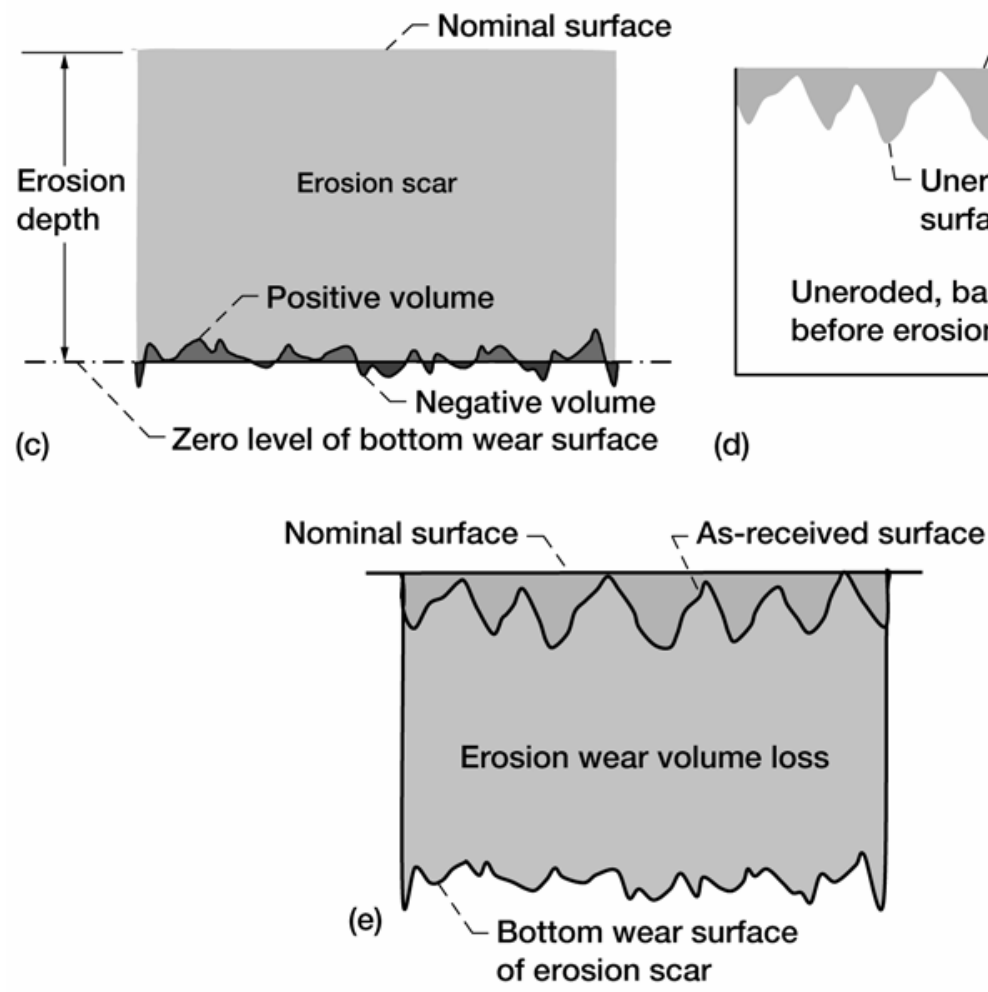

Figure 4. Depth-measuring method. (a) Designation of sampling area. (b) Erosion depth.

(c) Net missing volume of eroded area. (d) Natural volume of uneroded, bare surface.

(e) Erosion wear volume loss.

The natural volume of the uneroded, bare surface was obtained before erosion (fig. 4(d)). The natural volume of the uneroded, bare area was randomly measured at eight locations. Then, the total natural volume of the area, which is equal to the eroded wear scar area, was calculated. Because the surface roughness of uneroded, bare surface was relatively high, the natural volume of this surface could not be neglected.

Thus, the erosion wear volume loss, which is illustrated in figure 4(e), can be calculated as in equation (2). 


\section{Results and Discussion}

\section{Two-Layered Coatings and Arizona Road Dust}

The typical surface morphology and microstructures of the two-layered coatings deposited on the PMC vanes are shown in figs. 5(a) and (b).The two-layer-coated surfaces show a rough appearance. The typical average surface roughness $R a$ was measured over an area of 17 by $23 \mathrm{~mm}$. These values were 5.2 and $11.5 \mu \mathrm{m}$, respectively, for the uncoated PMCs and both two-layered coated PMCs. Aerodynamic analysis performed at Rolls-Royce Engines indicated that the increase in surface roughness for the coated bypass vanes did not decrease engine performance. Both two-layered coatings adhered well to the PMC substrates. Another indicator that these coatings adhered well was demonstrated during the thermal shock test. Coated samples were ramped from room temperature to $366 \mathrm{~K}$, were given an air quench, and then were cooled back to room temperature. This cycle was repeated 10 times. Both two-layered coatings remained intact after theses tests.

Figures 6(a) and (b) present typical scanning electron micrographs (SEMs) of the ARD particles. The ARD abrasive powder has a variety of shapes, from cubelike to ball-like with many edges. Figure 6(c) presents the grit size distribution of the ARD powder. The relative amounts of grits of various sizes included in the powder were 100 percent between 5 and $180 \mu \mathrm{m}, 63$ percent between 45 and $75 \mu \mathrm{m}$, and 35 percent coarser than $75 \mu \mathrm{m}$. The ARD powder contained primarily oxides, such as silica, aluminum oxide, iron oxide, calcium oxide, magnesia, and potassium oxide, and contained small amounts $(<0.1 \mathrm{wt} \%)$ of metallic elements, such as barium, manganese, and zinc. The ARD particle sizes were examined by screen tests using sieves, by atomic emission spectroscopy using inductively coupled plasma spectrometry, and by SEM using energy-dispersive $x$-ray spectroscopy.

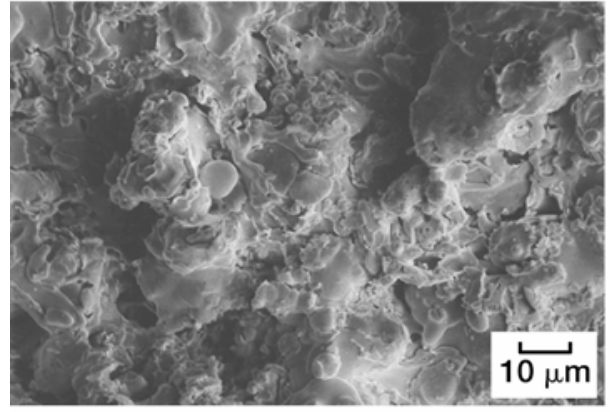

(a) Surface of WC-Co coating.

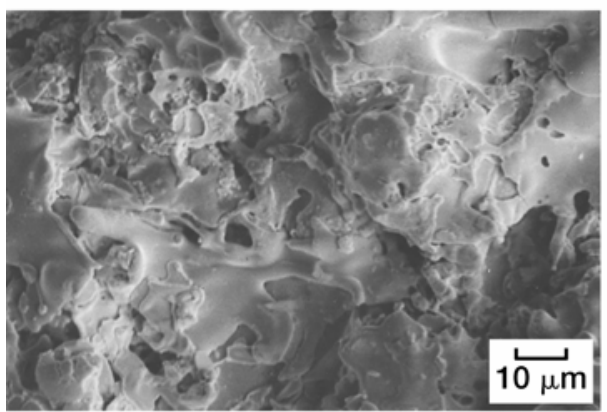

(b) Surface of WC-Co coating.

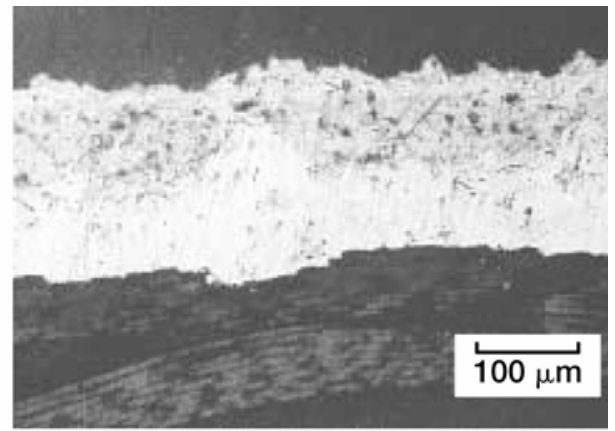

Cross section of coated PMC.

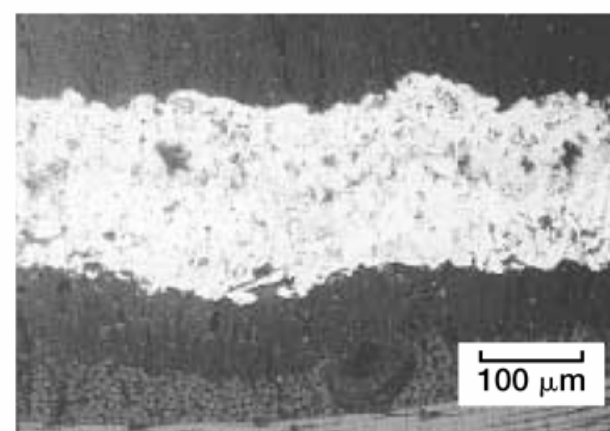

Cross section of coated PMC.

Figure 5. Typical surface morphology and microstructures of two-layered coatings deposited on PMCs. (a) WC-Co topcoat/bondcoat with no polymer on PMC. (b) WC-Co topcoat/bondcoat with polymer on PMC. 

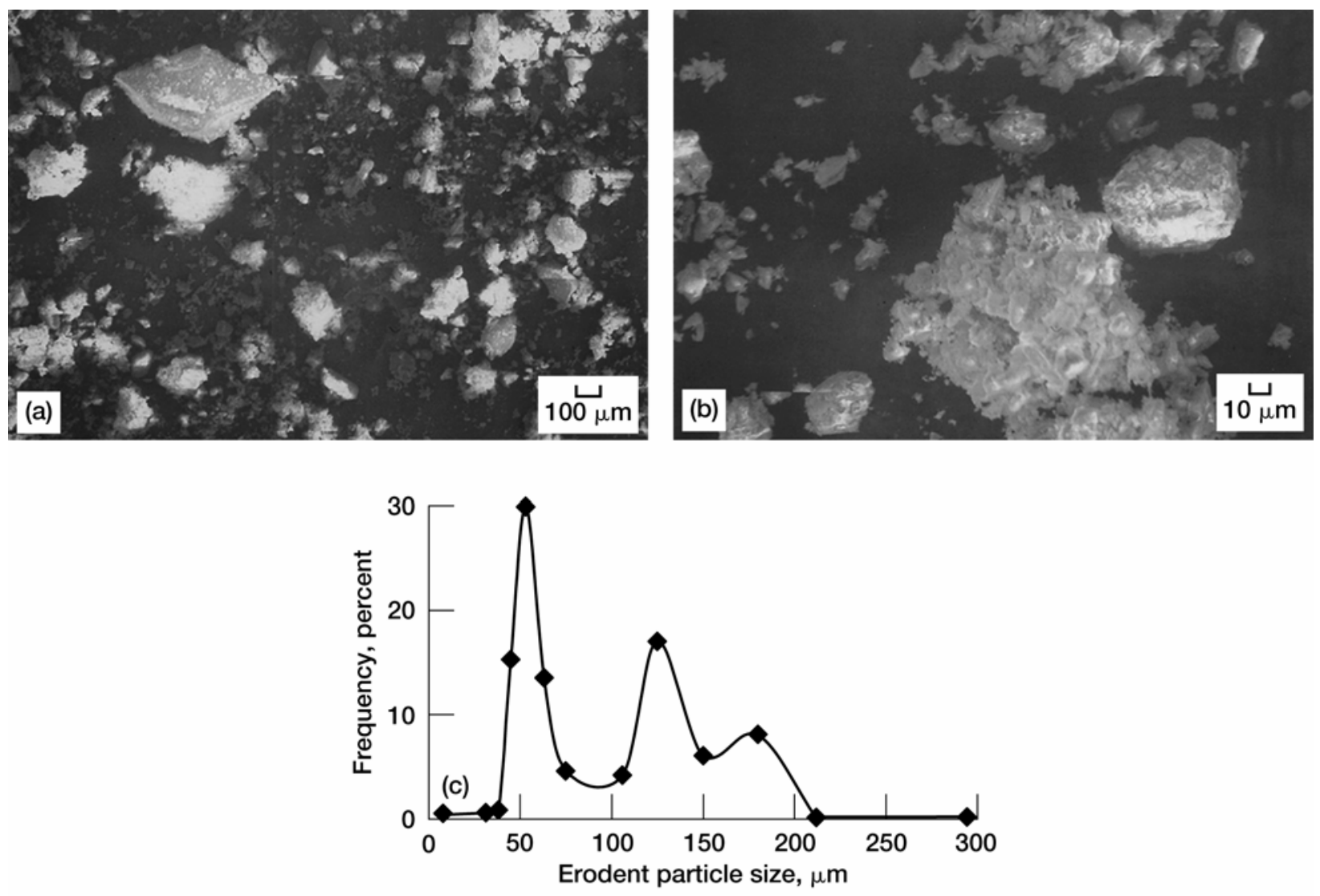

Figure 6. Scanning electron micrographs (SEMS) and particle size distribution of Arizona Road Dust (ARD). Low-magnification SEM. (b) High-magnification SEM. (c) Erodent particle size distribution of ARD.

\section{Stitching and Depth-Measuring Method}

When the rectangular-shaped groove (10 $\mu \mathrm{m}$ by $1 \mathrm{~mm}$ by $5 \mathrm{~mm}$ ) engraved in the step-height measurement standard was measured using the stitching method, its volume was $5.19 \times 10^{7} \mu \mathrm{m}^{3}$ with a standard deviation of $0.0243 \times 10^{7} \mu \mathrm{m}^{3}$; when it was measured using the depth-measuring method, its volume was $5.18 \times 10^{7} \mu \mathrm{m}^{3}$ with a standard deviation of $0.0265 \times 10^{7} \mu \mathrm{m}^{3}$. In other words, the measured data indicate no difference in the groove volumes measured by the two methods. Since the sampling area (1.9 by $6 \mathrm{~mm}$ ) was relatively small and the sampling surface was smooth and mirror-finished, the measurement time for the stitching method was similar to that for the depth-measuring method. Thus, either method can be used for the volume analysis of erosion wear scars.

Figure 7 presents the values of erosion wear volume losses measured by both the stitching method and the depth-measuring method for all 54 coated and uncoated PMC vane coupon specimens at 294 and $366 \mathrm{~K}$. These figures indicate that the correlation between the two measurement methods follows a linear relationship with a slope of 1 . Although the scatter plot slightly spreads out at the elevated temperature of $366 \mathrm{~K}$, the scatters at 274 and $366 \mathrm{~K}$ are relatively small. The measurement time for the stitching method was 10 times greater than that for the depth-measuring method because of sampling and stitching on the large-area, rough surface required for the vane specimens. 


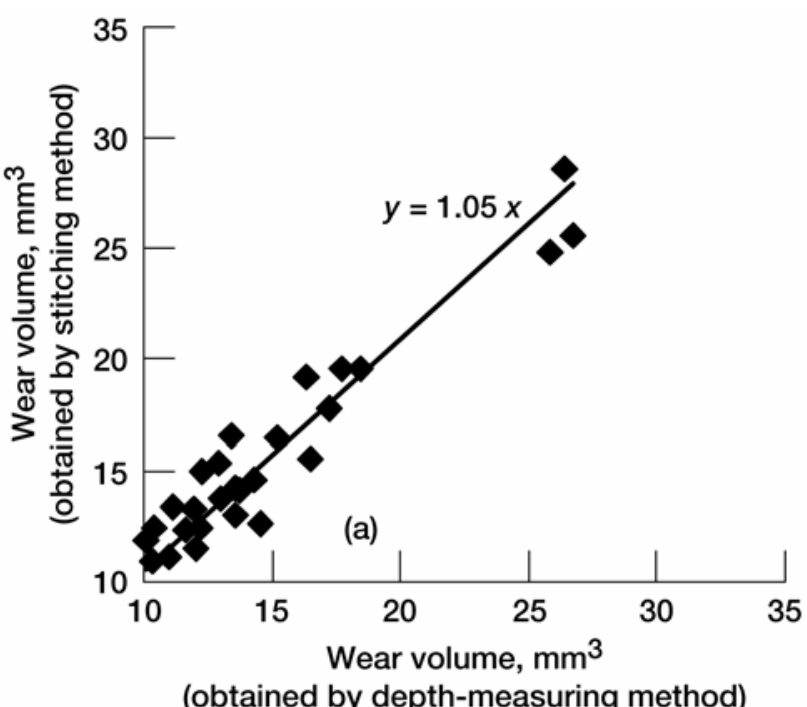

(obtained by depth-measuring method)

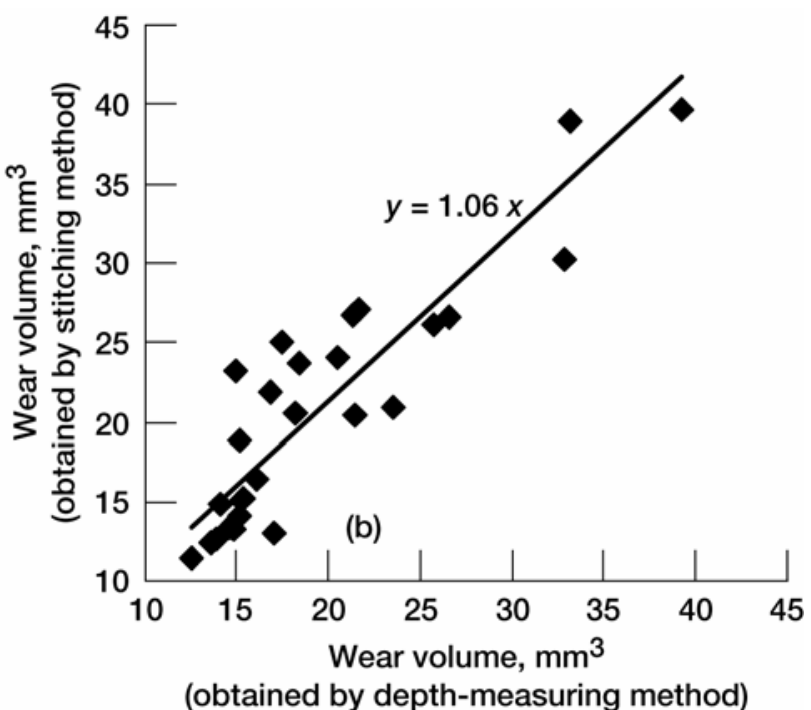

(obtained by depth-measuring method)

Figure 7. Wear volume losses for 54 coated and uncoated polymer matrix composite (PMC) vane specimens determined by stitching method (entire area sampling) and depth-measuring method (partial, limited area sampling) at two different temperatures. (a) $294 \mathrm{~K}$. (b) $366 \mathrm{~K}$.
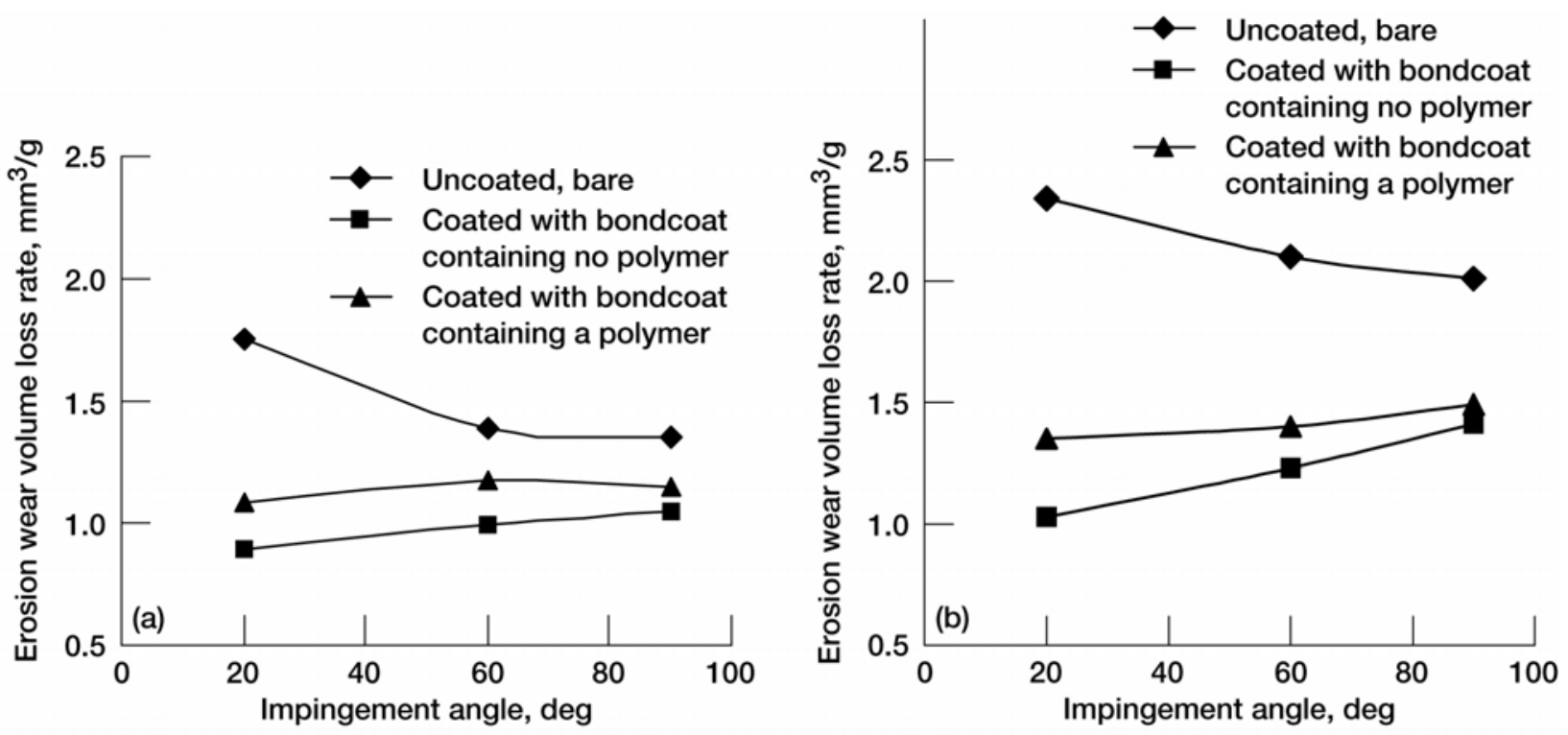

Figure 8. Erosion wear volume loss rate for coated and uncoated polymer matrix composite (PMC) vane specimens as a function of the impingement angles of solid abrasive particles (depth-measuring method) at two different temperatures. (a) 294 K. (b) 366 K. Note that each data point was an average value obtained from three erosion tests.

\section{Erosion Behavior}

Figure 8 presents average volume wear rates (volume removed per unit mass of erodent particles) as a function of the impingement angle for the WC-Co-coated PMC vane specimens and uncoated PMC vane specimens eroded at 294 and $366 \mathrm{~K}$. The erosion volume losses were obtained from the depth-measuring method. Three erosion tests were conducted with each material at each erosion condition. Theses data were averaged to obtain the erosion wear volume loss rate shown in figure 8 . Although the volume wear 
rates of both coated and uncoated PMCs depended on the impingement angle, the trends were different. The wear rates of the coated PMCs increased slightly with an increase of impingement angle, whereas those of the uncoated PMCs decreased, as illustrated in figure 8. It is known that brittle materials often show maximum wear for a normal incidence angle between the impact direction and the surface (ref. 11). The erosion of the WC-Co-coated PMCs had an angular dependence similar to that of brittle materials. In figure 8, the erosion of the coated PMCs depends on the impingement angle for a typical case where wear occurs by brittle fracture. When the impact of an erosive particle causes brittle fracture, material is removed from the surface by the formation and intersection of cracks. On the other hand, ductile materials commonly show maximum wear at a shallow impact angle, such as $20^{\circ}$, between the impact direction and the surface. The erosion of uncoated PMCs has a dependence on the impingement angle similar to that of ductile materials. In figure 8, the erosion of the uncoated PMCs depends on the impingement angle for a typical case where wear occurs by cutting and ploughing deformation by an abrasive particle. The sharp corner of the abrasive grain cuts or ploughs a chip from the surface.

PMCs with WC-Co coatings had enhanced erosion resistance (the reciprocal of the volume wear rate). The increase in erosion resistance was greater at lower impingement angles, such as $20^{\circ}$, at both 294 and $366 \mathrm{~K}$. The increase in erosion resistance is greater at the elevated temperature. The coatings were more beneficial at the lower impingement angle and the higher temperature. The increase in erosion resistance will contribute to longer vane lives, reduced erosion-related breakdowns, decreased maintenance costs, and increased vane reliability, which could lead to overall economic savings.

Figure 9 presents average depth wear rates (depth removed per unit mass of erodent particles) as a function of the impingement angle for the WC-Co-coated PMC vane specimens and the uncoated PMC vane specimens eroded at 294 and $366 \mathrm{~K}$. The erosion depths were obtained from the depth-measuring method. Similar to the erosion volume wear rates (fig. 8), the depth wear rates of both coated and
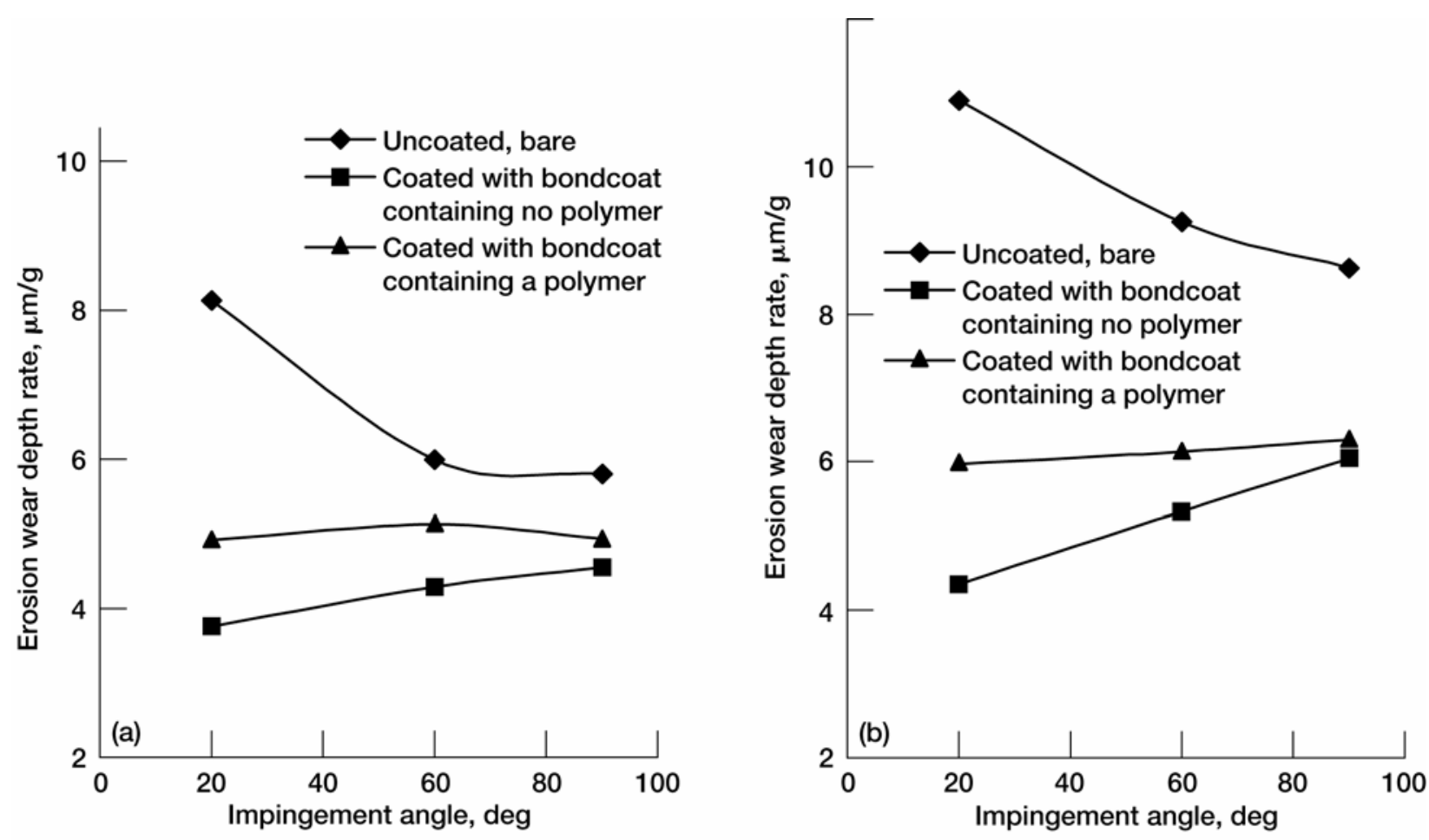

Figure 9. Erosion wear depth rate (depth removed per unit mass of erodent particles) for coated and uncoated polymer matrix composite (PMC) vane specimens as a function of the impingement angles of solid abrasive particles at two different temperatures. (a) $294 \mathrm{~K}$. (b) $366 \mathrm{~K}$. Note that each data point was an average value obtained from three erosion tests. 
uncoated PMCs depend on the impingement angle. The depth wear rates of the coated PMCs increase slightly as the impingement angle increases, whereas those of the uncoated PMCs decrease, as illustrated in figure 9.

Figure 10 presents the average surface roughness values of wear scars as a function of the impingement angle for the WC-Co-coated PMC vane specimens and uncoated PMC vane specimens eroded at 294 and $366 \mathrm{~K}$. At $294 \mathrm{~K}$, the surface roughness for both coated and uncoated PMCs generally increased with increasing impingement angle. The surface roughness values of the eroded, coated PMCs were similar to those of the eroded, uncoated PMCs. At $366 \mathrm{~K}$, the surface roughness for both coated and uncoated PMCs increased to its highest value at an impingement angle of $60^{\circ}$.

Abrasive particles always caused surface damage on the interacting surfaces of the coated and uncoated PMCs. This damage consisted of plastic deformation, cracks, craters, scratches, and pits. Figures 11(a) and (b) present examples of fractures in the eroded surface of the coated PMCs. The impact of the abrasive particles (fig. 11(a)) produced cracks and brittle-fractured facets in the coated PMC
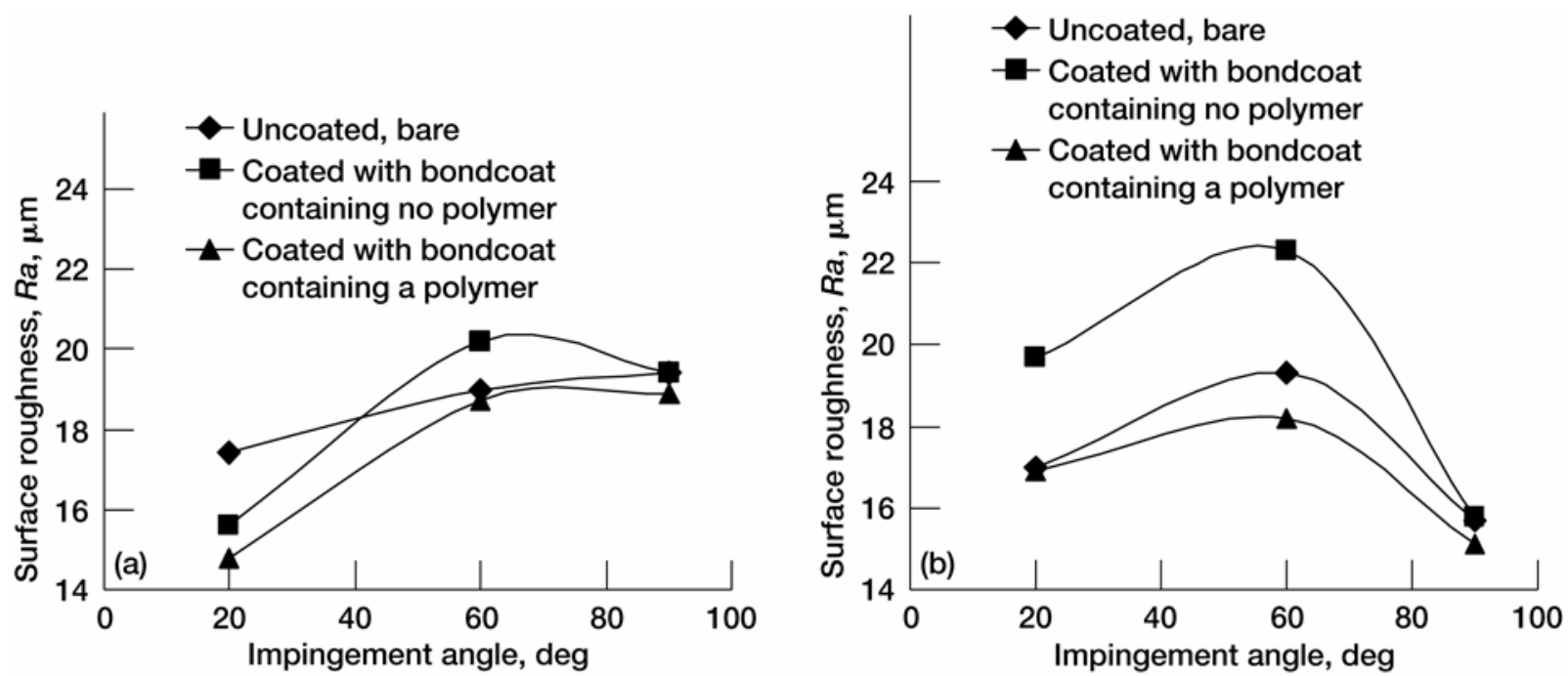

Figure 10. Surface roughness, $R a$, for eroded surfaces of coated and uncoated polymer matrix composite (PMC) vane specimens as a function of the impingement angles of solid abrasive particles at two different temperatures. (a) $294 \mathrm{~K}$. (b) $366 \mathrm{~K}$. Note that each data point was an average value obtained from three erosion tests.
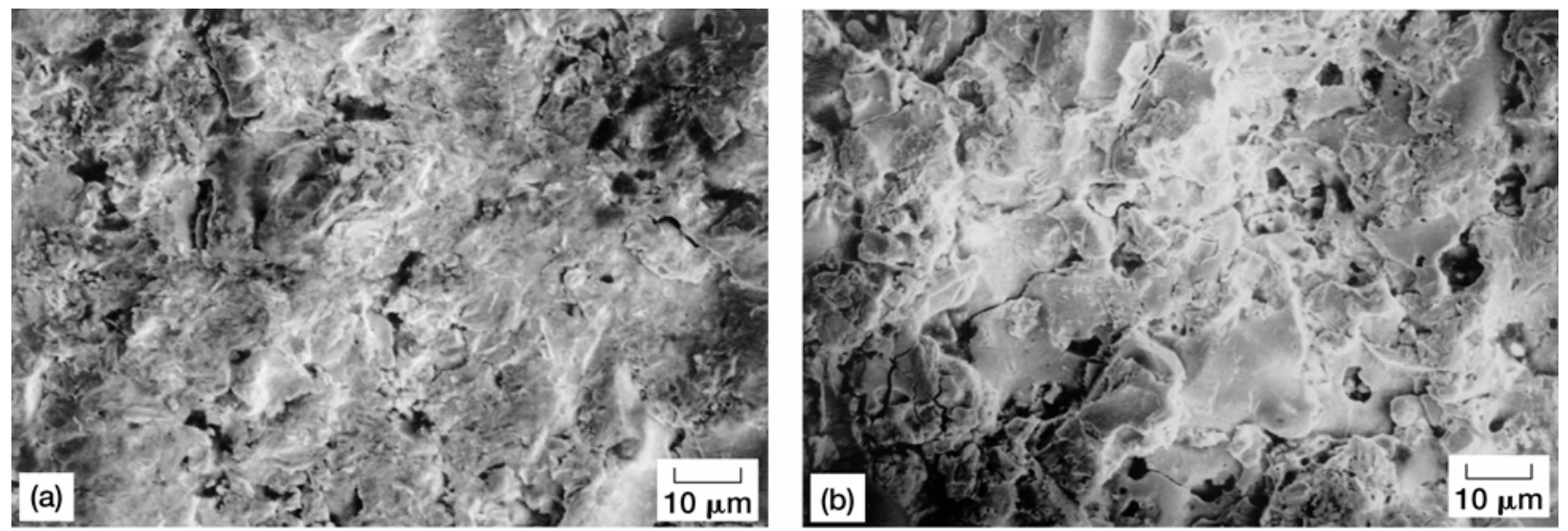

Figure 11. Surface damage in coated polymer matrix composites (PMCs) at $366 \mathrm{~K}$. (a) Coated PMC with a bondcoat containing no polymer. Impingement angle, $20^{\circ}$. (b) Coated PMC with a bondcoat containing a polymer. Impingement angle, $90^{\circ}$. 

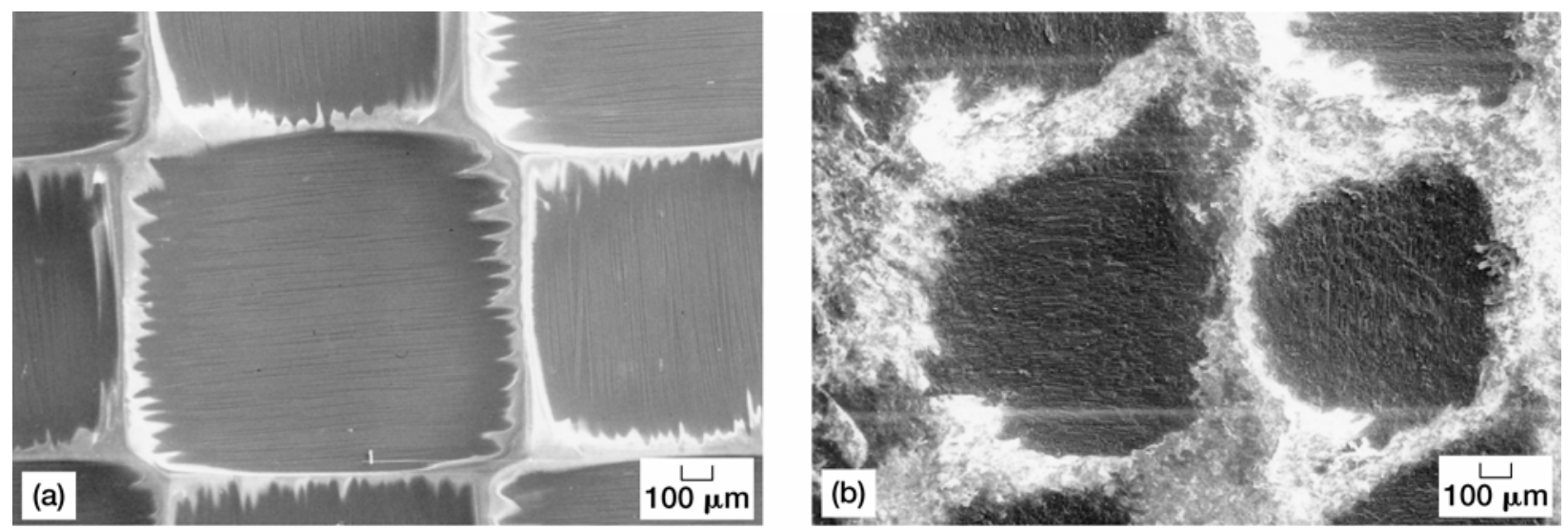

Figure 12. Surface damage in uncoated polymer matrix composites (PMCs) after erosion. Impingement angle, $20^{\circ}$; temperature, $294 \mathrm{~K}$. (a) A check pattern of squares of woven carbon fibers on eroded surface. (b) Wear damage on PMC.

surface. Apparently, the propagation of surface cracking is greater at an impingement angle of $90^{\circ}$ and a temperature of $366 \mathrm{~K}$ (fig. 11(b)).

Figures 12(a) and (b) present wear damage on the uncoated PMC. With the uncoated PMC, the erodent particles intensively removed the epoxy resin matrix material. In general, a checked pattern of squares of the woven carbon fibers were left behind (fig. 12(a)). In figure 12(b), some polymer matrix material was still present on the checked pattern of the woven carbon fibers.

\section{Temperature Effects}

Temperature influences the erosion wear volume loss and wear depth of coated and uncoated PMCs as shown in figures 8 and 9. Both the volume wear rate and the depth wear rate increased as the temperature increased. For the uncoated PMCs, both the volume wear rate and the depth wear rate increased much more than they did for the coated PMCs. The coated PMCs with polymer content in their bondcoats had higher volume and depth wear rates than did the coated PMCs with no polymer content in their bondcoats. The volume and depth wear rates of the coated and uncoated PMCs investigated herein increased in the following order: coated PMCs with no polymer content in their bondcoats, coated PMCs with polymer content in their bondcoats, and uncoated PMCs.

Temperature also influences the surface roughness of coated and uncoated PMCs eroded at impingement angles of $20^{\circ}, 60^{\circ}$, and $90^{\circ}$. The temperature effect of surface roughness depends on the impingement angle. At an impingement angle of $20^{\circ}$, the surface roughness of the coated PMCs increased as the temperature increased, whereas the surface roughness for the uncoated PMCs remained unchanged. More wear of coated PMCs occurred at high temperatures by the cutting and ploughing deformation of the erodents, resulting in surface roughening. At an impingement angle of $60^{\circ}$, the surface roughness for the coated PMCs with no polymer content in their bondcoats and for the uncoated PMCs increased as the temperature increased, whereas the surface roughness for the coated PMCs with polymer content in their bondcoats decreased slightly. The surface roughness for the uncoated PMCs remained unchanged. In contrast, at an impingement angle of $90^{\circ}$, the surface roughness for all the coated and uncoated PMCs decreased as the temperature increased. In this case, wear of the coated PMCs occurred by brittle fracture, and small fragments chipped off the coating surfaces, resulting in surface smoothing. 


\section{Summary of Results}

The following results were obtained from this investigation of the erosion behavior of coated and uncoated polymer matrix composites.

1. When the volume of the rectangular-shaped groove engraved in the step-height measurement standard was measured by the stitching method and by the depth-measuring method, no difference in the measured groove volume was found.

2. When the erosion wear volume losses of the vane specimens measured by the stitching method and the depth-measuring method were plotted, the correlation between the measured values followed a linear relationship with a slope of 1 . This suggests that an even loss of substance occurred over each wear scar during erosion. The stitching method and/or the depth-measuring method can be chosen for erosion volume loss measurements; however, the stitching method required 10 times more measurement time than the depth-measuring method because of sampling on the large-area, rough surface.

3. The wear rates of the coated PMCs increased with an increase of impingement angle, whereas those of the uncoated PMCs decreased. For the coated PMCs, wear occurred predominantly by brittle fracture. For the uncoated PMCs, wear occurred predominantly by the cutting and ploughing deformation of an abrasive particle.

4. The WC-Co coatings deposited on the PMCs enhanced erosion resistance. The increase in erosion resistance was greater at lower impingement angles, such as $20^{\circ}$, at both 294 and $366 \mathrm{~K}$. The increase in erosion resistance was greater at the elevated temperature of $366 \mathrm{~K}$. Thus, the coatings were more beneficial at the lower impingement angle and the higher temperature.

5. Similar to the erosion volume wear rates, the depth wear rates of the coated PMCs increased with an increase of impingement angle, whereas those of the uncoated PMCs decreased.

6. The surface roughness for both coated and uncoated PMCs generally increased with increasing impingement angle at $294 \mathrm{~K}$. The surface roughness values of the eroded, coated PMCs were similar to those of the eroded, uncoated PMCs. At $366 \mathrm{~K}$, the surface roughness for both coated and uncoated PMCs reached its highest value at an impingement angle of $60^{\circ}$.

7. In the coated PMC surface, the impact of abrasive particles produced cracks and brittle-fractured facets. In the uncoated PMCs, the cutting and ploughing action of the abrasive particles produced plastically deformed surfaces.

8. Temperature influenced the erosion wear volume loss and wear depth of coated and uncoated PMCs: Both the volume wear rate and the depth wear rate increased as the temperature increased. The increases in both the volume and depth wear rate for the uncoated PMCs were much greater than those for the coated PMCs. The volume and depth wear rates of the coated and uncoated PMCs increased in the following order: coated PMCs with no polymer content in their bondcoats, coated PMCs with polymer content in their bondcoats, and uncoated PMCs. 
9. The effect of temperature on the surface roughness varied: At an impingement angle of $20^{\circ}$, the surface roughness for the coated PMCs increased as the temperature increased, whereas the surface roughness for the uncoated PMCs remained unchanged. At an impingement angle of $60^{\circ}$, the surface roughness values for the coated PMCs with no polymer content in their bondcoats increased with temperature, whereas surface roughness values for the coated PMCs with polymer content in their bondcoats decreased. At an impingement angle of $90^{\circ}$, the surface roughness values for all the coated and uncoated PMCs decreased as the temperature increased.

\section{Concluding Remarks}

The two-layered (WC-Co topcoat and bondcoat) coatings deposited on the PMCs enhanced erosion resistance. They reduced the erosion wear volume loss by a factor of nearly 2 . The twofold increase in erosion resistance will contribute to longer vane lives, reduced related breakdowns, decreased maintenance costs, and increased product liability. Thus, the coatings could lead to overall economic savings.

Noncontact, optical interferometry can be used to accurately determine the erosion wear volume loss of PMCs with multilayered structures while preserving the specimens.

\section{References}

1. D. Wilson, in: Polyimide, eds. H. Stenzenberger and P. Hergenrother (Chapman and Hall, London, 1990) 187.

2. T. Stevens, Mater. Engrg., 107 (11) (1990) 29-32.

3. S.M. Hoff, Aerospace Engrg., 15 (2) (1995) 27-30.

4. J.K. Sutter, Research \& Technology 1999, NASA/TM-2000-209639 (2000) 22-23. http://www.grc.nasa.gov/WWW/RT1999/5000/5150sutter.html

5. D.L. Chambers et al., Surf. Coatings Technol., 41 (1990) 315-323.

6. K. Miyoshi et al., Measurements of Erosion Wear Volume Loss on Bare and Coated Polymer Matrix Composites. NASA/TM-2003-212628.

http://gltrs.grc.nasa.gov/cgi-bin/GLTRS/browse.pl?2003/ TM-2003-212628.html

7. S.K. Naik et al., Erosion Resistant Coatings for Polymer Matrix Composites in Propulsion Applications, SAMPE 2003 International Symposium, Vol. 2 (2003) 1526-1539. Also, James K. Sutter et al., NASA/TM-2003-212201 (2003). http://gltrs.grc.nasa.gov/cgi-bin/GLTRS/browse.pl?2003/TM-2003-212201.html

8. W. Tabakoff and G. Simpson, AIAA Paper 2002-0373, 1 (2002) 1-16.

9. W. Tabakoff and A. Hamed, NATO-RTO-MP-34 (9/2000).

10. P.J. Caber, S.J. Martinek, and R.J. Niemann, WYKO Technical Bulletin 1993-27A (WYKO, Tucson, AZ, 1993) 1-14.

11. I.M. Hutchings, Tribology: Friction and Wear of Engineering Materials (CRC Press, Boca Raton, FL, 1992). 


\begin{tabular}{|c|c|}
\hline \multicolumn{2}{|c|}{ REPORT DOCUMENTATION PAGE } \\
\hline \multicolumn{2}{|c|}{$\begin{array}{l}\text { Public reporting burden for this collection of information is estimated to average } 1 \text { hour per response, including the time for reviewing instructions, searching existing data sources, } \\
\text { gathering and maintaining the data needed, and completing and reviewing the collection of information. Send comments regarding this burden estimate or any other aspect of this } \\
\text { collection of information, including suggestions for reducing this burden, to Washington Headquarters Services, Directorate for Information Operations and Reports, } 1215 \text { Jefferson } \\
\text { Davis Highway, Suite 1204, Arlington, VA 22202-4302, and to the Office of Management and Budget, Paperwork Reduction Project (0704-0188), Washington, DC 20503. }\end{array}$} \\
\hline 1. AGENCY USE ONLY (Leave blank) & \begin{tabular}{|r|l} 
2. REPORT DATE & 3. \\
April 2004 &
\end{tabular} \\
\hline \multicolumn{2}{|c|}{$\begin{array}{l}\text { 4. TITLE AND SUBTITLE } \\
\text { Assessment of Erosion Resistance of Coated Polymer Matrix Composites } \\
\text { for Propulsion Applications }\end{array}$} \\
\hline \multicolumn{2}{|c|}{$\begin{array}{l}\text { 6. AUTHOR(S) } \\
\text { Kazuhisa Miyoshi, James K. Sutter, Richard A. Horan, Subhash K. Naik, } \\
\text { and Randall J. Cupp }\end{array}$} \\
\hline $\begin{array}{l}\text { 9. SPONSORING/MONITORING AGEI } \\
\text { National Aeronautics and Sp } \\
\text { Washington, DC 20546-00 }\end{array}$ & $\begin{array}{l}\text { NAME(S) AND ADDRESS(ES) } \\
\text { Administration }\end{array}$ \\
\hline
\end{tabular}

Kazuhisa Miyoshi and James K. Sutter, NASA Glenn Research Center; and Richard A. Horan, Subhash K. Naik, and Randall J. Cupp, Allison Advanced Development Company/Rolls-Royce Corporation, Indianapolis, Indiana 46206. Responsible person, Kazuhisa Miyoshi, organization code 5160, 216-433-6078.

12a. DISTRIBUTION/AVAILABILITY STATEMENT

12b. DISTRIBUTION CODE

Unclassified - Unlimited

Subject Category: 27

Distribution: Nonstandard

Available electronically at http://gltrs.grc.nasa.gov

This publication is available from the NASA Center for AeroSpace Information, 301-621-0390.

13. ABSTRACT (Maximum 200 words)

The erosion behavior of tungsten carbide-cobalt (WC-Co) coated and uncoated polymer matrix composites (PMCs) was examined with solid particle impingement using air jets. Erosion tests were conducted with Arizona road dust impinging at $20^{\circ}, 60^{\circ}$, and $90^{\circ}$ angles at a velocity of $229 \mathrm{~m} \cdot \mathrm{s}^{-1}$ at both 294 and $366 \mathrm{~K}$. Noncontact optical profilometry was used to measure the wear volume loss. Results indicate that the WC-Co coating enhanced erosion resistance and reduced erosion wear volume loss by a factor of nearly 2 . This should contribute to longer wear lives, reduced related breakdowns, decreased maintenance costs, and increased product reliability.

\section{SUBJECT TERMS}

Materials; Polymer matrix composites; Inlet guide vane; Erosion-resistant coatings; Optical interferometry

\begin{tabular}{|c|c|c|c|}
\hline $\begin{array}{c}\text { 17. SECURITY CLASSIFICATION } \\
\text { OF REPORT } \\
\text { Unclassified }\end{array}$ & $\begin{array}{c}\text { 18. SECURITY CLASSIFICATION } \\
\text { OF THIS PAGE } \\
\text { Unclassified }\end{array}$ & $\begin{array}{c}\text { 19. SECURITY CLASSIFICATION } \\
\text { OF ABSTRACT } \\
\text { Unclassified }\end{array}$ \\
\hline
\end{tabular}

NSN 7540-01-280-5500 

